\title{
EL DIÁLOGO JUDICIAL COMO DIÁLOGO HERMENÉUTICO: PERSPECTIVAS DE LOS DERECHOS HUMANOS EN EL DIÁLOGO DE LAS ALTAS CORTES Y LA JURISDICCIÓN INTERNA
}

\author{
JUDICIAL DIALOGUE AS HERMENEUTICAL DIALOGUE: HUMAN RIGHTS \\ PERSPECTIVE IN THE DIALOGUE BETWEEN HIGH COURTS AND LOCAL \\ JURISDICTION
}

\author{
Efrén Vázquez Esquivel* \\ Jaime Fernando Cienfuegos Sordo ${ }^{* *}$
}

SUMARIO: 1. El impacto de la globalización y la posmodernidad en la comprensión y desarrollo del derecho. 2. Los orígenes del diálogo judicial. 3. Los presupuestos teóricos del diálogo hermenéutico. 4. La ruptura del diálogo judicial en la jurisprudencia de la SCJN.

\section{RESUMEN}

Este artículo tiene como propósito mostrar que, desde el punto de vista teórico, el diálogo judicial tiene la estructura de un diálogo hermenéutico. Sin embargo, en la práctica, sea porque el legislador así lo dispone o por una incorrecta interpretación de la ley, no siempre se conducen los procesos judiciales conforme a las directrices del diálogo hermenéutico. El eje de esta exposición, fundada en la hermenéutica filosófica, es que, por medio de restricciones a los derechos humanos contenidas en ciertas tesis jurisprudenciales emitidas por la Corte mexicana, ésta trata de evitar que los jueces, con fundamento en artículo 1 de la Constitución, recurran al sistema de control difuso para inaplicar una ley que contraviene a un tratado internacional que protege derechos humanos. Se concluye sosteniendo que el hecho de que la Corte se aparte de sus propios criterios para evitar que los jueces inapliquen una ley, por sí mismo no es algo que necesariamente tenga que ver con una «sobreinterpretación» o actitudes tiránicas. Ello en virtud de que, entre otras razones, la situación hermenéutica sobre la que se resuelve nunca es la misma. Pero, abandonar un criterio por otro, atendiendo, desde luego a la situación hermenéutica, en una interpretación correcta nunca es para vulnerar derechos, sino para cumplir a cabalidad con el «designio» del máximo tribunal y de todos los juzgadores: la realización de la justicia.

\section{PALABRAS CLAVE}

Hermenéutica filosófica. Diálogo judicial. Diálogo hermenéutico. Interpretación.

\begin{abstract}
The purpose of this paper is to show that, from a theoretical point of view, the judicial dialogue has the same structure as a hermeneutic dialogue. Nonetheless, in practice, whether because the legislator so provides it or because of a wrong interpretation of the law, the judicial processes are

\footnotetext{
* Doctor en Derecho por la Universidad Autónoma de Nuevo León, México. Profesor de Filosofía del Derecho e Interpretación y Argumentación Jurídicas, en esta misma Universidad (San Nicolás de los Garza, NL, México); miembro del Sistema Nacional de Investigadores. E-mail: efren23@hotmail.com

** Alumno del Programa de Doctorado en Derecho Constitucional y Gobernabilidad de la Facultad de Derecho y Criminología de la Universidad Autónoma de Nuevo León (San Nicolás de los Garza, NL, México). E-mail: jaime.cienfuegoss@gmail.com
} 
not always followed by the guidelines of the hermeneutic dialogue. The main axis of this exhibition, founded in philosophical hermeneutics, is that, by making restrictions to the human rights contained in certain precedents issued by the Mexican Supreme Court, it tries to avoid that the judges appeal to the judicial dialogue for the effective protection of human rights. It is concluded that the fact that the Court stays away of its own principle is not, by itself, something that necessarily has to do with an "over interpretation" or tyrannical attitudes. Amongst other reasons, the hermeneutic situation by which it is solved is never the same. But, abandoning one approach for another, in response, of course, to the hermeneutic situation, in a correct interpretation is never to violate rights, but to fully comply with the "purpose" of the Supreme Court and of all the judges: the implementation of justice.

\section{KEYWORDS}

Philosophical Hermeneutics. Judicial dialogue. Hermeneutics dialogue. Interpretation. 


\section{EL IMPACTO DE LA GLOBALIZACIÓN Y LA POSTMODERNIDAD EN LA COMPRENSIÓN Y DESARROLLO DEL DERECHO}

Este artículo tiene como propósito mostrar que, desde el punto de vista teórico, concretamente desde la perspectiva de la hermenéutica filosófica, el «diálogo judicial», el cual históricamente emerge en los contextos de la postmodernidad (o hipermodernidad) ${ }^{1}$ y el capitalismo avanzado que trajo consigo la globalización económica, tiene la estructura de un diálogo racional, y, por ende, de un «diálogo hermenéutico».

Sin embargo, en la práctica, ya sea porque la legislación así lo dispone o por una incorrecta interpretación de la ley, no siempre se conducen los procesos judiciales conforme a las directrices del diálogo hermenéutico, esto por un lado; y, por el otro - como se expondrá en el subtítulo número cuatro con ciertas tesis jurisprudenciales de la Suprema Corte de Justicia de la Nación (SCJN) -, no son pocas las ocasiones en que en el diálogo que el máximo tribunal de la nación sostiene con sus inferiores de la jurisdicción interna y con los organismos supranacionales que protegen los derechos humanos, en contra de los principios del diálogo hermenéutico y de la misma ley y disposiciones constitucionales, se aleja de la racionalidad hermenéutica, con lo cual se cancela la posibilidad de la realización del diálogo hermenéutico.

Los mencionados fenómenos han venido a producir, entre otros de sus efectos de muy diversa índole, un mayor debilitamiento de la racionalidad positiva que fundamenta la teoría jurídica de la modernidad. Y, con ello, el derrumbamiento de algunos de sus conceptos jurídicos fundamentales, ahora vacíos de contenido; conceptos que ya no representan la facticidad que hoy fluye en el mundo de lo social y de la vida.

Ante la incertidumbre que generan todos estos cambios, no pocos juristas, olvidando la necesidad de verdades universales, obviamente, sólo bajo ciertas situaciones y en ciertos valores que protegen y estimulan el desarrollo de los derechos humanos, apelan a la defensa del nacionalismo y el derecho patrio para tratar de hacer valer el viejo utillaje del positivismo jurídico. Otros más hablan de la necesidad de un cambio de paradigma para comprender todos estos cambios; pero, paradójicamente, los resultados de sus deliberaciones muestran el sello de la matriz epistemológica del positivismo, por lo que, sin desconocer sus serios intentos, los avances en cuanto a los elementos que la estructura del diálogo judicial requiere (para lograr un verdadero diálogo), son exiguos.

\footnotetext{
${ }^{1}$ En los términos de Habermas, donde la modernidad, es un proyecto inacabado, por tanto, no sería posible hablar de posmodernidad (2004, p. 54 et seq.).
} 
También, aunque esto será materia de otro estudio, son exiguos los resultados del diálogo judicial que en la práctica se produce entre las cortes. Pues, ni siquiera bajo las reticencias que impone al «diálogo» la doctrina iuspositivista ${ }^{2}$, no siempre se produce entre dichos tribunales - y entre éstos y los organismos supranacionales que protegen los derechos humanos -, un verdadero diálogo. En efecto, no pocas veces, ante las limitaciones de una sólida formación hermenéutica, en vez de un diálogo racional, lo que se da entre tribunales de las diversas jurisdicciones transfronterizas es una fiel reproducción de sentencias.

El diálogo judicial, para que sea tal, tiene que incorporar la reelaboración conceptual de los últimos tiempos. Desde nuestro punto de vista, los conceptos jurídicos que más han sido afectados por la internacionalización de la producción y la liberalización de mercancías, bienes y servicios, que ha traído consigo la globalización económica, con apoyo del nuevo conservadorismo ideológico postmoderno que se anuncia como el fin de las ideologías - creándose así un nuevo orden que traspasa las fronteras de los países -, son los conceptos de soberanía, el cual ahora se determina preponderantemente por el mercado ${ }^{3}$ (FERRAJOLI, 2003, p. 313-24); el de fuentes del derecho, antes determinado sólo por factores del ámbito territorial (CARBONELL, 2008, p. 204 et seq.); y el de norma suprema como concepto fundante básico y dador único de sentido y validez de una multiplicidad de normas, pertenecientes a un determinado sistema jurídico (KELSEN, 1982, p. 202).

\footnotetext{
2 Esta alusión al positivismo jurídico, y las que se encuentran más adelante, las hacemos considerando que, independientemente de las discrepancias entre las diferentes escuelas que se colocan bajo esta denominación, respecto a los elementos esenciales que integran su canon de cientificidad, todas comparten una o varias posturas entre las que cabe aludir: la exigencia de una base empírica, la exclusión de los juicios de valor, la objetivación del método, el método como único criterio de verdad, la plenitud del ordenamiento jurídico, la tesis mecanicista (subsunción o de deducción) en la aplicación del derecho, etc. lo cual puede corroborarse ampliamente en las distintas teorías de la interpretación jurídica. Esto incluso en aquellas que presentan algunos acercamientos hermenéuticos como la declarativa de la imposibilidad de la única respuesta correcta, por ejemplo, en Kelsen (1982, p. 351-2) o en Hart (1992, p. 164), quienes rehúyen de la ontologización de la hermenéutica y el problema histórico como factor de comprensión decisivo de lo que nos interpela. Lo mismo acontece en el marco de la teoría de la argumentación de mayor impacto (ALEXY, 1997, p. 61), pues, no obstante su apertura a factores metajurídicos, no deja de percibir los objetos inteligibles desde la perspectiva del pensar calculador, lo que en M. García Calvo se denomina como el salto del positivismo sobre su propia sombra (1994, p. 62 et seq.). La mejor opción, creemos, se encuentra en Heidegger, quien acertadamente señala que el proyecto científico de Galileo y Newton fue pensado para las ciencias naturales (cuyo canon de cientificidad sigue iluminando a la ciencia jurídica), y no para las ciencias del hombre (o del espíritu). Los presupuestos teóricos de estos dos grandes pensadores, toman en consideración "la determinación de las legalidades conforme a las cuales los puntos de masa se mueven en el espacio y tiempo, pero no tomando en consideración en absoluto a aquél ente que llamamos ser- humano [...] La ciencia natural sólo puede constatar al ser-humano como algo que está simplemente ahí en la naturaleza. Surge la pregunta: ¿A caso podemos encontrar así al ser-humano?” (2007, p. 51-3).

${ }^{3}$ Sobre la influencia del mercado en la determinación de un nuevo concepto de soberanía que traspasa las fronteras, y, a la vez, genera condiciones para la sustitución del Estado social por el Estado mínimo, fundado éste en la lógica de una nueva teoría contractualista individualista, véase MÜLLER, 1992, en KERN, Lucian y MÜLLER, Hans Peter, p. 208 et seq.
} 
Por las razones que expondremos en el siguiente apartado, todos estos cambios históricos que ha traído el nuevo orden económico al Derecho, son favorables a la elevación de la cultura jurídica de la comunidad internacional. Pues han venido a impactar positiva y considerablemente en el ámbito de la función jurisdiccional de los países del centro y la periferia, en razón de que los órganos encargados de la impartición de justicia se ven compelidos a tomar en cuenta en sus decisiones las directrices normativas e interpretativas trazadas por organismos surpranacionales, principalmente en materia de protección de derechos humanos, con lo cual, al dotar a las decisiones judiciales de un mayor índice de racionalidad jurídica, se amaina un poco la crisis del positivismo jurídico que se sigue viendo en la comunidad jurídica internacional.

De ahí entonces que, el fenómeno de la globalización económica que se despliega en el Estado neoliberal, no sólo ha incentivado el aludido conservadurismo ideológico que envuelve a la actividad comercial dependiente del mundo de la técnica, de lo que ya se han ocupado y se siguen ocupando economistas, politólogos, sociólogos y filósofos, (abundan los estudios sobre el tipo de prácticas discursivas del neoliberalismo económico, usadas para la manipulación políticoideológica, lo mismo que sobre el debate postmodernidad versus hipermodernidad) ${ }^{4}$, sino también ha venido a estimular el desarrollo de la ciencia jurídica. Lo que prueba que, históricamente, en los procesos de globalización no sólo se intercambian mercancías y servicios profesionales, sino también ideas: cultura. En el caso que nos ocupa, el proceso globalización económica relacionada a los ya mencionados fenómenos, ha traído consigo el replanteamiento de los conceptos de derecho y justicia desde una perspectiva global y universal. Es decir, tomando en consideración, para la reformulación de estos conceptos por medio de un diálogo racional, elementos de las diversas tradiciones de la comunidad internacional.

Así, entonces, los juristas estamos haciendo lo propio, y en el caso de los autores de este ensayo, nuestro compromiso es con la crítica jurídica. Ésta nos convoca a voltear la mirada hacia los paradigmas emergentes aparecidos en la segunda mitad del siglo XX, que buscan dar mejores respuestas a los problemas de la ciencia jurídica que el positivismo jurídico ya no ha podido resolver ${ }^{5}$.

De manera particular, nuestra mirada se fija en la hermenéutica filosófica, con cuyo utillaje teórico pensamos el Derecho en busca de su desarrollo y del sentido de lo humano. La crítica

\footnotetext{
${ }^{4}$ Los economistas y politólogos han tratado de comprender y explicar las grandes contradicciones de los modelos de integración regional, los cuales paradójicamente abren las fronteras a la circulación de mercancías, bienes y servicios, y al mismo tiempo, sin consideración alguna de violaciones a los Derechos humanos, las cierran a la libre circulación de personas que luchan por su subsistencia.

${ }^{5}$ Una visión que trata esta cuestión se encuentra en Filosofía del Derecho y paradigmas epistemológicos: De la crisis del positivismo a las teorías de la argumentación y sus problemas de Pedro Serna (2006, p. 64 et seq.)
} 
jurídica nos compele a no ignorar estos complejos fenómenos, fuertemente relacionados entre sí, que caracterizan la época actual, ya que son éstos los que determinan los cambios que ha venido sufriendo el Derecho como ciencia y como sistema de normas de un determinado Estado.

Cambios en las legislaciones y prácticas jurídicas de los países de la periferia, inspirados en las legislaciones de los sistemas del Common Law, que erróneamente han sido percibidos por algunos juristas como cambios de paradigmas, cuando la verdad es que el abordaje teórico para percibir los cambios de la legislación no ha dejado de ser el positivismo y neopositivismo jurídico en sus diversas tendencias.

Es bien sabido que en T. S. Khun, el concepto «paradigma» en la ciencia hace referencia a una manera específica de percibir algo, en los ámbitos de la sensibilidad o la inteligibilidad. Esta manera de percibir, que en la teoría de la ciencia adquiere diferentes denominaciones, fundamenta a una realización científica consumada de la ciencia normal, la cual sirve de modelo a los investigadores. La creencia en un determinado paradigma, concepto que en T. S. Khun es también entendido como sinónimo de teoría, es, por lo general, reticente a la crítica. Sin embargo:

[...] en los tiempos de revolución, cuando la tradición científica normal cambia, la percepción que el científico tiene de su medio ambiente debe ser reeducada, en algunas situaciones en las que se ha familiarizado, debe aprender a ver una forma (Gestalt) nueva. Después de que lo haga, el mundo de sus investigaciones parecerá, en algunos aspectos, incompatible con el que habitaba antes (KHUN, 2013, p. 177).

No obstante, en la comunidad jurídica internacional, aunque con mucho menos intensidad en los países del Common Law, el paradigma que sigue imperando es el positivismo jurídico en sus diversas versiones. Por esta razón insistimos una vez más: no es verdad que, por lo menos en México, con la institucionalización del nuevo sistema penal acusatorio, entre otros cambios que ha habido a la legislación mexicana, nos encontramos ante un nuevo paradigma, pues

[...] cuando cambian los paradigmas, el mismo mundo cambia con ellos. Guiados por un nuevo paradigma, los científicos adoptan nuevos instrumentos y buscan en lugares nuevos. Lo que es todavía más importante, durante las revoluciones los científicos ven cosas nuevas y diferentes al mirar con instrumentos conocidos y en lugares en los que ya habían buscado. (KHUN, 2013, p. 176).

Nuestro propósito, por tanto, es reflexionar sobre la dimensión jurídica de todos estos cambios desde la perspectiva de la hermenéutica filosófica, mismos que hasta ahora, en lo que se refiere a las prácticas jurisprudenciales en el Estado constitucional de derecho, sólo han encontrado su fundamento teórico en el neoconstitucionalismo.

Ciertamente esta nueva doctrina, en la que de mejor manera se fundamenta el Estado constitucional de derecho, independientemente de las diferencias de su conceptualización, 
representa un nuevo modo de percibir el Derecho constitucional en la que, por medio de recursos técnicos-interpretativos que incorporan las nociones de «proporcionalidad», «ponderación»», «razonabilidad», etc. - lo que en realidad no es nada nuevo, ya que estos valores intelectuales, relacionados por Gadamer al problema hermenéutico de la aplicación, se encuentran en Aristóteles - (GADAMER, 2005, p. 387 et seq.) el «derecho» se vuelve dúctil (ZAGREBELSKY, 2009, p. 1415). Pero desde nuestro punto de vista, estimamos que el neoconstitucionalismo, al seguir anclado al canon epistemológico del positivismo jurídico en el que la interpretación no deja de asumirse desde un sistema de reglas objetivadas y sin horizonte, sin visos de acercamiento al canon hermenéutico contemporáneo, éste no proporciona medios para avanzar lo suficiente hacia el logro de un mayor índice de racionalidad jurídica en las decisiones judiciales.

Es cierto también que el neoconstitucionalismo, fundado en cualesquiera de las diferentes vertientes de la filosofía positiva, al postular la interpretación moral de la Constitución y poner en juego reglas y principios en el proceso de interpretación, muestra una apertura que posibilita superar la idea de interpretación como proceso de deducción o subsunción; pero tal cosa, por lo general, sólo se puede dar en la jurisdicción constitucional y en aquellos casos que, siguiendo la doctrina de Hart, son considerados como casos difíciles (hard cases).

Así las cosas, en los tiempos de la hipermodernidad (para otros, postmodernidad) en los que a la vez aparece la era de la nueva koiné en la comprensión del arte y la cultura, la poesía y la historia, etc., en el campo del Derecho y las prácticas judiciales el principio que aún rige en la interpretación es el de la vieja hermenéutica: in claris non fit interpretatio («lo claro no necesita interpretación»), no el de la hermenéutica contemporánea, cuyas raíces se encuentran en Schleiermacher: «el otro, para mí, es una completa oscuridad, por tanto, en toda comunicación oral o escrita yo necesito de la hermenéutica para la comprensión». Y si la interpretación aparece como necesaria, sólo entonces, nos encontramos siempre ante un caso difícil, cosa que estimamos puede ser superada si en los designios del Derecho pensamos desde la perspectiva de la nueva koiné.

\section{LOS ORÍGENES DEL DIÁLOGO JUDICIAL}

El concepto de diálogo judicial es de reciente data, en el aspecto teórico-jurídico, aparece en la obra de A. Aarnio, para quien en el proceso de justificación externa de las decisiones judiciales éste tiene como propósito esencial la búsqueda del convencimiento racional de los auditorios, respecto a la interpretación realizada en una decisión judicial (AARNIO, 1977); mas no persuadir a los auditorios, como se suele hacer, recurriendo a medios no racionales. 
En el aspecto práctico, es en el contexto de los fenómenos de la globalización, de naturaleza económica; y el de la posmodernidad (o hipermodernidad), de naturaleza cultural, ideológica, política y filosófica; vinculados estos dos fenómenos al de la regulación jurídica internacional de la postguerra (que dio origen en 1945 a la Declaración Universal de los Derechos Humanos), en el que, en la segunda mitad de los años 90, aparecen los primeros estudios sobre la práctica del derecho constitucional global. Estudios en los que, como refiere Tania Groppi, se reflexiona sobre el creciente rol que desempeñan los jueces constitucionales como protagonistas de la vehiculación-jurídica-conceptual transfronteriza, haciendo ver el uso de "argumentos asistemáticos, esto es, la referencia, cada vez más frecuente en sus dediciones judiciales, al Derecho internacional o extranjero, comprendidas las decisiones de otras cortes constitucionales” (2011, p. 216).

De manera más precisa, el uso del concepto «diálogo judicial» en la práctica de los operadores jurídicos ha tenido sus primeros escarceos - de manera particular en la protección de los derechos humanos, por parte de los organismos supranacionales - a raíz del tráfico comercial que se produce con la celebración del Tratado de la Unión Europea, el 1 de noviembre de 1993. Así es que, el desarrollo de un ius commune europeo y últimamente la búsqueda de un ius commune en América Latina, es, en la época actual, uno de los subproductos de la apertura comercial y el pluralismo cultural, moral y político de los diversos países que integran la aldea global. El ius commune ha requerido de los operadores jurídicos, principalmente de los jueces, un cambio de actitud para aceptar e incorporar en sus razonamientos, esgrimidos en sus decisiones judiciales, ciertos valores de la esfera de lo jurídico y precedentes de otros sistemas jurídicos. Todo esto, como parte del desempeño de la función jurisdiccional, realizada ahora a la luz de un nuevo constitucionalismo (o neoconstitucionalismo), que ofrece mejores posibilidades para el logro de la realización de justicia constitucional.

Siguiendo las reflexiones de R. Bustos, el nuevo constitucionalismo del mundo globalizado o «régimen constitucional-pluralista», se caracteriza por la ausencia de la tradicional norma última claramente identificable y, con ello, además, por la no existencia de una jurisdicción última que resolviera la cuestión. En esta tesitura, para el profesor de la Universitat Pompeu Fabra, en una Constitución pluralista es requisito de congruencia que no puede haber autoridad última dotada de 
un poder exclusivo de imperio, delimitada por el ámbito territorial, sino más bien «una red de autoridades últimas» (2012, p. 49-50) .

Se faltaría al principio de congruencia, en la aldea global, la exigencia de una norma última en el nuevo constitucionalismo. Lo exigible sería, de acuerdo a la lógica de la globalización que analiza Bustos Gisbert, «una red de normas últimas», y, como consecuencia de lo anterior, de acuerdo al autor citado, tampoco puede haber una jurisdicción última, "sino una red de jurisdicciones y las soluciones a los conflictos de tales redes aun compartiendo un mismo sentido serán diferentes siempre que no sea posible alcanzar una solución de síntesis válida para todos los órdenes constitucionales en disputa” (2012, p. 50).

Cabe señalar como ejemplo de este fenómeno, la inserción de las llamadas cláusulas de apertura en los actuales textos constitucionales, lo cual ha traído como resultado una transformación en la tradición de sistemas de fuentes del derecho fundadas en el positivismo jurídico, a lo que también nos hemos referido. En virtud de que la teoría jurídica de la modernidad ha perdido su fuerza explicativa, las fuentes del derecho piden ser pensadas de nuevo. Peter Häberle, dice sobre este tema que:

La ideología que preconiza el "monopolio del Estado" en materia de fuentes jurídicas termina por serle al Estado constitucional un concepto tanto más ajeno, cuanto más próximo esté del propio concepto de "Estado constitucional cooperativo", puesto que éste no adopta ya ninguna posición preponderante de monopolio, ni de jurisdicción, ni de exégesis jurídica, sino que va abriéndose de forma progresiva a procedimientos jurídicos internacionales y a la interpretación de la normativa jurídica efectuada a nivel internacional o supraestatal. (HÄBERLE, 2002, p. 288).

Ahora bien, para los estudiosos del Derecho constitucional inscritos en cualquiera de las vertientes del neoconstitucionalismo, todos estos cambios que afectan el plexo de valores en que se fundamenta la teoría jurídica de la modernidad; dando origen, desde los primeros años de la década del 70 del siglo pasado, a la pluralidad de la razón y con ésta al surgimiento de un pluralismo cultural, jurídico y político - con todo y la matriz epistemológica positivista que de una u otra manera influye en estos estudios -, significan un desarrollo de la ciencia jurídica. Pues, como es sabido, el campo teórico de una ciencia cualquiera sólo florece cuando éste da en qué pensar meditativa y cuantitativamente; cuando su utillaje teórico posibilita identificar problemas y problematizar, encarar fenoménicamente el mundo de la vida y las cosas que tienen que ver con el sentido de lo humano.

\footnotetext{
${ }^{6}$ Rafael Bustos Gisbert nos dice que “el panorama constitucional es radicalmente diferente del que ha sido objeto de la Teoría constitucional clásica. La norma constitucional nacional ha dejado de ser inmune frente a las normas extraestatales [...]” (2012, p. 13).
} 
A riesgo de ser reiterativo, ni la ciencia jurídica, ni la práctica jurídica y jurisprudencial se han visto deterioradas por los fenómenos de la globalización y la hipermodernidad, vinculados, como antes dijimos, al fenómeno de la regulación jurídica internacional de la postguerra; antes al contrario, estos cambios generan nuevos problemas teóricos, estimulan el pesar meditativo, y, con ello, se ha dado un paso más en la evolución del Estado constitucional de derecho, que exige una permutación en las practicas llevadas a cabo por los actores jurídicos, entre los cuales los jueces ocupan un lugar preponderante (FERRAJOLI, 2010, p. 29).

Cosa muy distinta es que la evolución de la ciencia jurídica y la del Estado constitucional de derecho pudieran encontrar serios obstáculos para un pleno desarrollo, debido a que en todos estos estudios se palpa un olvido de la perspectiva hermenéutica. Los enfoques para el análisis de estos fenómenos siguen siendo las diferentes vertientes del positivismo, doctrina que, ciertamente, ha hecho progresar las ciencias naturales; pero en las ciencias del espíritu, entre ellas el Derecho, muestra, como principales deficiencias: a) una indiferencia al mundo de la subjetividad - cuando que la subjetividad, como objeto de análisis, es lo propio del Derecho -; y b) la objetivación no sólo del método, con lo cual, sobre todo en el Derecho resulta imposible encontrar el sentido de lo humano, sino también del mismo sujeto.

Un ejemplo de las consecuencias del olvido de la hermenéutica, y con ello la objetivación del método y el sujeto, es la tesis sostenida por R. Bustos Gisbert, según la cual "la presencia de jurisprudencias constitucionales contradictorias entre los diversos lugares constitucionales no es sólo inevitable, sino característico de un ordenamiento constitucional pluralista” (2012, p. 49). El enfoque positivista sólo posibilita ver que la contradicción de tesis jurisprudenciales constitucionales en diferentes lugares es, como consecuencia de la Constitución pluralista, algo inevitable. No percibe el problema hermenéutico de la aplicación; no advierte las razones por las que, de manera normal, cuando se interpreta algo se interpreta de manera diferente. Ello en razón de que la interpretación, hecha desde la perspectiva positivista, es meramente reproductiva, no productiva, en donde el intérprete, en función de un «designio» - que no es otro más que la búsqueda de la realización de la justicia -, hace valer su opinión.

No obstante, tenemos que reconocer que los esfuerzos intelectuales efectuados desde la perspectiva del paradigma positivista, entrelazado en algunos aspectos con las teorías de la argumentación, ha logrado problematizar y representar conceptualmente los elementos que caracterizan los fenómenos del neoliberalismo y la globalización; y a la vez, en las transacciones del mundo de la globalización y la postmodernidad (o hipermodernidad), han podido aportar instrumentos teóricos para resolver conflictos transfronterizos. 
Uno de estos elementos teóricos es el concepto de «diálogo judicial» (que, desde nuestro punto de vista, por las razones que se expondrán en el siguiente apartado sería mejor referirse a éste como un diálogo hermenéutico judicial), el cual ha servido para solventar las tensiones que se producen entre los distintos órganos jurisdiccionales, encargados de aplicar tanto las cartas constitucionales como los tratados internacionales; o en términos generales, la constitución pluralista.

En la doctrina del constitucionalismo contemporáneo, el «diálogo judicial», también llamado «diálogo institucional» (NUÑEZ TORRES, 2007, p. 159) o «puentes jurisdiccionales dialógicos», es, hasta ahora, el mejor medio para diluir tensiones entre distintas jurisdicciones; para producir confianza a los distintos actores de la aldea global, entre ellos los grandes inversionistas; y para dotar a las decisiones judiciales un índice superior de racionalidad jurídica. Sobre este punto, R. Bustos Gisbert sostiene que:

Las tensiones entre lugares constitucionales no se resuelven tanto con la imposición de posturas sobre otras, cuanto mediante procedimientos de diálogo conducentes a soluciones mutuamente satisfactorias para todas las instancias interpretativas (y para los textos que tales instancias acatan e interpretan) implicadas (2012, p. 110-111) ${ }^{7}$.

Independientemente de lo que dejamos dicho al principio: no en todos los casos se produce el diálogo, ya que en no pocos asuntos lo que se aprecia es una reproducción de sentencias, la citada tesis de Bustos Gisbert nos lleva a aceptar una nueva realidad que, aunque puede pesar sobre muchos, pues, a decir verdad, no es fácil comprender el significado y sentido de todos estos cambios, es sin más una realidad en la que hoy vivimos y tenemos que saber comprenderla y explicarla.

Dicha realidad ha sido comprendida y expuesta por Anne-Marie Slaughter, profesora de la Universidad de Harvard, quien en uno de sus ensayos expone lo siguiente en las primeras líneas: “Courts are talking to one another all over the world” (SLAUGHTER, 1994, p. 99 et seq.) ${ }^{8}$. Sí, que bueno que los tribunales están hablando el uno al otro a todo el mundo; pero para que haya una verdadera comprensión entre estos hablantes y no sólo una «reproducción» de sentencias realizada a la luz de un paradigma interpretativo positivista, es necesario que en el diálogo judicial se produzca

\footnotetext{
${ }^{7}$ El autor hace referencia a la experiencia europea en donde existen sedes de interpretación diversas y cada una supremas respecto de sus propias tablas de derechos, que si bien no resulta idéntica si es similar a la que actualmente se vive en el orden jurídico mexicano.

${ }^{8}$ El ensayo realizado por la autora constituye una importante propuesta de clasificación que puede servir como base para el posterior desarrollo del tema, así lo admite la autora al establecer que: “This article is intended as an exploratory essay, and thus relies on a relatively small universe of examples. Even an anecdotal survey suggest, however, that many important instances of transjudicial communications could be identified. It is my hope that labeling and analyzing this phenomenon, even on an exploratory basis, will stimulate further research and discussions”. En: http://goo.gl/zN2tEo. Fecha de consulta: 1 de octubre de 2013.
} 
un salto para que éste sea un diálogo hermenéutico, cuya características, las expondremos en el siguiente apartado.

La misma autora nos proporciona ejemplos, hasta en términos de porcentajes, de la manera como en el tribunal supremo de la república africana de Zimbabue y el Tribunal de Derechos Humanos de Europa se venido realizando dicho diálogo, textualmente dice lo siguiente:

The Supreme Court of Zimbabwe cites decisions of the Europe Court of Human Rights to support its determination that corporal punishment of an adult constitutes cruel and unusual punishment and that corporal punishment of a juvenile is unconstitutional. The European Court of Justice and the European Court of Human Rights cite one another's decisions; the Inter-American Court of Human Right looks frequently to the European Court's caselaw. Approximately 60\% of the citations of Quebec decisions, including French authors and decisions, common law decisions and authors from a range of countries (SLAUGHTER, 1994, p. 99 et seq.).

Y más adelante dice, también de manera textual:

Within both the European Union and the Council of Europe, courts are entering into forms of judicial dialogue. The most advanced form of such interaction is the recent call by the German Constitutional Court for a "relationship of co-operation" with de European Court of Justice, in wich both entities would form a kind of partnership in delimiting the boundaries of the competences of the European Community [...] (2012, p. 100).

De todo lo anterior, y de manera particular de estas dos últimas citas, desprendemos la siguiente conclusión:

a. El concepto de «diálogo judicial» y su implementación entre las cortes de diferentes países y los organismos supranacionales, con todo y que en algunos casos sólo se produce una reproducción de sentencias, es algo que se ha venido desarrollando, aun de manera precaria, como consecuencia de los fenómenos de la globalización comercial y la postmodernidad (o hipermodernidad). El diálogo judicial se ha producido, de manera preponderante, entre las instituciones europeas y los países que forman parte de la Unión Europea.

b. El «diálogo judicial» ha ingresado de manera paulatina en los países que integran la Organización de Estados Americanos por medio de la Corte Americana de los derechos humanos con órgano jurisdiccional del Sistema Interamericano de Protección de derechos humanos.

c. Las Cortes Constitucionales nacionales, sobre todo en materia de derechos humanos y protección del medio ambiente, cada vez utilizan más la jurisprudencia comparada para justificar sus decisiones, cosa que se encuentra debidamente documentada, como es el caso de la profesora de la Universidad de Harvard ya citada. 
He aquí nuestras consideraciones del «diálogo judicial». Enfatizamos el aspecto internacional porque es en este contexto en el que éste se ha dado, determinado por diversos factores de la globalización. En el ámbito interno, por lo menos en México, culturalmente no existen condiciones para que éste se dé, los jueces comunes son jueces de legalidad, y el sistema, de diversas maneras, produce en ellos temor a «pensar» en pro del designio de la realización de la justicia. No hace mucho en el Tribunal Superior de Justicia del Estado de Nuevo León, por ejemplo, se tenía como criterio para distinciones y ascensos que los argumentos contenidos en la sentencia del juez no fueran derribados, con carácter de definitividad, por algún medio de impugnación.

Por supuesto que hay excepciones, una de ellas es la del magistrado Carlos Emilio Arenas Bátiz, el primero en el país que, con fundamento en la reforma del artículo 1 constitucional de 10 de junio de 2011, orientado por el marco del sistema de control difuso de la constitucionalidad otorgado por dicha reforma a un juez común, inaplicó una ley en el expediente penal No. 43/11, por considerar que contravenía un tratado internacional en materia de derechos humanos.

Este uno de los casos en el que se muestra el desenvolvimiento del diálogo entre la SCJN; un tribunal supranacional; y un órgano de la jurisdicción interna. Pero la SCJN, al parecer opta por la defensa del sistema de control de la constitucionalidad concentrado, ya que ha emitido criterios jurisprudenciales $^{9}$ en el sentido de inducir a los jueces colocar la Constitución en una jerarquía superior a los tratados internacionales, con lo que éstos se ven limitados para recurrir al sistema de control difuso para inaplicar leyes que contravengan tratados internacionales en materia de derechos humanos, teniendo como fundamento para ello el $2^{\circ}$ párrafo del artículo 1 constitucional que establece: "Las normas relativas a los derechos humanos se interpretarán de conformidad con esta Constitución y con los tratados internacionales de la materia favoreciendo en todo tiempo a las personas la protección más amplia”.

Desde el punto de vista teórico, en cambio, sí se advierte la presencia de instituciones jurídicas para que se produzca el diálogo judicial, tanto en directrices constitucionales como en cuerpos de leyes procesales. Dicho en otros términos, por lo menos en algunas partes del proceso judicial, sí se existe de manera virtual la estructura del diálogo judicial. Pues bien, ahora pasaremos a exponer de manera sintética lo que, algunos de los expertos, ha dicho sobre el diálogo judicial.

\footnotetext{
${ }^{9}$ Un ejemplo paradigmático, entre otros, de la manera de controlar a los jueces por la jurisprudencia es la contradicción de tesis 293/2011, de la cual deriva la jurisprudencia P./J. 20/2014 (10a.), visible en la Décima Época de la Gaceta del Semanario Judicial de la Federación, Libro 5, Tomo I, abril de 2014, p. 202, Registro IUS: 2006224.
} 


\title{
2.1 EL DIÁLOGO JUDICIAL EN EUROPA
}

Se puede afirmar que el constitucionalismo europeo ${ }^{10}$ (BUSTOS GISBERT, 2012, p. 1) relacionado con la creación de un ius comune, el cual abarca tanto las modalidades de ejercicio del poder como la protección de los derechos fundamentales (BURGORGUE-LARSEN, 2012, p. 25) constituye el ordenamiento jurídico en el que, con mayor amplitud, se ha desarrollado el «diálogo judicial». La profesora de Derecho público en la Escuela de Derecho de la Sorbona, Laurence Burgorgue Larsen, sostiene sobre este punto lo siguiente:

\begin{abstract}
En realidad, en Europa, la construcción, el desarrollo y el fortalecimiento del llamado "constitucionalismo europeo" o "derecho constitucional europeo" se desarrolla sobre todo mediante un diálogo judicial con una multitud de "actores" jurisdiccionales - las jurisdicciones nacionales (de los jueces "ordinarios" a los jueces constitucionales) y, por supuesto, no se puede ignorar el Tribunal Europeo de Derechos Humanos, lo que da lugar a un entramado sumamente variado de relaciones. El constitucionalismo europeo es sobre todo "dialogado", lo que permite, entre otras cosas, superar las barreras, los retrasos de la integración generada por revisiones caóticas de los tratados [...] (2012, 30-31).
\end{abstract}

De igual forma, dicho diálogo ha dado como resultado un proceso de Cross-Fertilization of the Legal Systems, entendido como la exportación e importación de los conceptos e ideas fundamentales de un sistema jurídico nacional a otro; de un sistema jurídico regional a otro; de un sistema jurídico internacional (o uno regional) a otros sistemas jurídicos de carácter nacional, (SLAUGHTER, 1994, p. 117) produciéndose con esto un sincretismo jurídico-cultural que, de una o de otra, contribuye general confianza en los diferentes actores de la comunidad jurídica internacional.

Respecto a lo que en este artículo mentamos como sincretismo jurídico-cultural, el jurista británico Francis J. Jacobs denomina “fertilización cruzada”, la cual se produce entre las naciones a través del diálogo judicial. Tampoco hay desatino en esta denominación, pues lo que se produce en los sistemas jurídicos, a través del diálogo judicial, por medio del cual se incorporan recíprocamente elementos de un sistema jurídico a otro, es el mejoramiento de un producto. De manera textual el autor citado dice:

It is clear, I think, that within the EU there has been a remarkable degree of judicial dialogue and cross-fertilization, all the more significant in view of the great differences in

\footnotetext{
${ }^{10}$ A respecto Bustos Gisbert explica que "Desde la II Guerra Mundial se está viviendo, fundamentalmente aunque no sólo en Europa un lento proceso de constitucionalización de ordenamientos jurídicos de ámbito superior al estatal. Este proceso ha aparecido en paralelo a la progresiva integración de los Estados europeos, pero ha recibido un fuerte respaldo (ampliando su base territorial) como consecuencia del heterogéneo proceso de interrelación mundial de la vida colectiva que conocemos hoy con el ya manido nombre de globalización”.
} 
the legal systems of the Member States and their historical foundations (JACOBS, 2003, p. $556)^{11}$.

En este sentido, es en la Unión Europea donde el «diálogo judicial» ha tenido su mayor desarrollo; al grado de que algunos autores hacen depender el desarrollo del ius commune europeo de dicha interacción entre los órganos jurisdiccionales trasnacionales y los países miembros ${ }^{12}$. (BUSTOS GISBERT, 2012, p. 51).

\subsection{EL DIÁLOGO JUDICIAL EN AMÉRICA}

La doctrina de un ius constitututionale commune surge a juicio del jurista E. Ferrer MacGregor $^{13}$ de la misma doctrina establecida por la Corte Interamericana de Derechos Humanos, la cual se da por medio de la consolidación del control difuso de convencionalidad mismo que nace en el caso Alomacid Arellano vs. Chile en 2006:

124. La Corte es consciente que los jueces y tribunales internos están sujetos al imperio de la ley y, por ello, están obligados a aplicar las disposiciones vigentes en el ordenamiento jurídico. Pero cuando un Estado ha ratificado un tratado internacional como la Convención Americana, sus jueces, como parte del aparato del Estado, también están sometidos a ella, lo que les obliga a velar porque los efectos de las disposiciones de la Convención no se vean mermadas por la aplicación de leyes contrarias a su objeto y fin, y que desde un inicio carecen de efectos jurídicos. En otras palabras, el Poder Judicial debe ejercer una especie de “control de convencionalidad” entre las normas jurídicas internas que aplican en los casos concretos y la Convención Americana sobre Derechos Humanos. En esta tarea, el Poder Judicial debe tener en cuenta no solamente el tratado, sino también la interpretación que del mismo ha hecho la Corte Interamericana, intérprete última de la Convención Americana.

$\mathrm{Al}$ parecer, es esta la ejecutoria con la que da inicio la doctrina jurisprudencial del «control difuso de convencionalidad» misma que posteriormente ha sido desarrollada y matizada por la misma Corte Interamericana de Derechos Humanos en diversas resoluciones.

En consecuencia, se aprecia con meridiana claridad que, también debido a los factores referidos en el punto 1 de esta exposición, en América emerge la necesidad de un auténtico «diálogo judicial»; y aunque con pasos lentos, el diálogo en este continente se ha venido

\footnotetext{
${ }^{11}$ http://www.tilj.org/content/journal/38/num3/Jacobs547.pdf. Fecha de consulta: 1 de octubre de 2013.

${ }^{12}$ A respecto Joseph H. H. Weiler y Ulrich R. Haltern han señalado el "constitucionalismo europeo" se plasma en que las lineas jurisdiccionales deben ser objeto de una conversación constitucional, no de un "diktat" constitucional.

${ }^{13}$ A decir de este jurista mexicano, "la trascendencia de la nueva doctrina sobre "el control difuso de convencionalidad" es de tal magnitud, que probablemente en ella descanse el futuro del Sistema Interamericano de Protección de los Derechos Humanos y, a su vez, contribuirá al desarrollo constitucional y democrático de los Estados nacionales de la región. La construcción de un auténtico "diálogo jurisprudencial" - entre los jueces nacionales y los interamericanos-, seguramente se convertirá en el nuevo referente jurisdiccional para la efectividad de los derechos humanos en el siglo XXI. Ahí descansa el porvenir: en un punto de convergencia en materia de derechos humanos para establecer un auténtico ius constitucional commune en las Américas” (FERRER MAC-GREGOR, 2012, p. 429).
} 
desarrollando de la misma manera como se viene desarrollando en Europa, entre los países parte del Sistema Interamericano de Derechos Humanos.

Tal como lo ha señalado Víctor Bazán, existe una verdadera necesidad de establecer vínculos jurisdiccionales dialógicos entre los jueces internos y la jurisdicción interamericana, al respecto, dicho autor concluye diciendo que:

\begin{abstract}
El control de convencionalidad y sus "circunstancias" no deberían pensarse ni desarrollarse en el marco de una estricta y exclusiva lógica unidireccional desde la Corte IDH hacia las jurisdicciones nacionales, sino que es preciso generar las condiciones para profundizar "diálogos jurisprudenciales críticos" de los tribunales nacionales entre sí y de ellos con la Corte IDH. [...] [La necesidad de edificar paulatinamente una razonable sinergia interjurisdiccional se plantea partiendo de la premisa de que no existe una relación jerárquica formal entre aquellas instancias jurisdiccionales, sino una deseable convivencia en conexión axiológica y jurídicamente cooperativa en la línea de una hermenéutica pro persona, en tanto ella son copartícipes necesarias de un objetivo convergente: fortalecer cualitativamente la tutela y la realización de los derechos básicos, lo que supondrá optimizar la salvaguarda de la dignidad humana (BAZÁN, 2012, p. 64).
\end{abstract}

Sobre este punto hay que mencionar que Bazán ya habla de puentes dialógicos. Es correcto hablar de «puente dialógico», porque la palabra «puente» remite, en la tradición de la cultura occidental, al límite de una frontera cultural, al punto de encuentro de dos o más líneas divisorias de tradiciones diferentes que, por medio de un puente, se produce la posibilidad de que se comuniquen entre sí. De ahí entonces que, el diálogo entre tradiciones jurídicas diferentes, como en todo auténtico diálogo, no puede ser unilateral ni previamente jerarquizado, sino que debe existir una cooperación entre las distintas jurisdicciones encargadas de ejercer un control difuso de la constitución y de la convención.

Ahora bien, en América, tal como nos hace recordar E. Ferrer Mac-Gergor (2012, p. 426) la misma Corte Interamericana de Derechos Humanos ha reconocido que el «diálogo judicial», o «diálogo jurisprudencial», como lo llama dicho órgano, no se da únicamente de manera vertical y de arriba hacia abajo, sino que el «diálogo» es posible de muy diversas formas entre los órganos jurisdiccionales en que integran el Sistema Interamericano:

4. Durante 2010 el “diálogo jurisprudencial” entre la Corte Interamericana, órganos judiciales superiores a nivel interno. Este diálogo ha tenido dos efectos concretos y palpables en los últimos años. Por un lado, a nivel interno se puede verificar un creciente número de países que incorporan los estándares interamericanos de derechos humanos fijados por la Corte. Por el otro, la Corte se ve enormemente beneficiada de la jurisprudencia producida a nivel local, lo que ayuda además al desarrollo de su propia jurisprudencia. Esto genera una dinámica que enriquece la jurisprudencia del Tribunal y fortalece la vigencia de los derechos humanos en todos los Estados del hemisferio, ya que la protección internacional de los derechos humanos encuentra aplicación directa en el 
ámbito interno por parte de los tribunales locales o de cualquier órgano estatal encargado de impartir justicia ${ }^{14}$.

Pues bien, es indudable que el «diálogo judicial» se encuentra en un proceso de desarrollo en el contexto jurídico interamericano. Es incuestionable que el diálogo judicial necesita, para su consolidación, una evolución en la Teoría constitucional, en donde habrá que examinar de nuevo, de manera preponderante, por un lado, el problema de la jerarquía normativa y los conceptos de soberanía y fuentes del derecho; y por el otro, los paradigmas interpretativos con los que operan los operadores jurídicos ${ }^{15}$.

En esta tesitura, coincidimos en la observación que hace Ferrer Mac-Gergor: es verdad que los países que cada vez más incorporan criterios normativos e interpretativos de la CIDH lo hacen porque, por una u otra razón se ven beneficiados; pero también, dicho organismo supranacional, por algunas buenas razones incorpora criterios de los países.

Esto nos hace pensar (en contra de quienes bajo la bandera de un viejo concepto de soberanía perciben que someterse a los criterios de organismos supranacionales protectores de derechos humanos es algo que menoscaba la soberanía nacional) en que lo importante es el imperio de la razón, sea cual sea su fuente de procedencia. Pues si el derecho es prudencia, como narra Platón de los antiguos (PLATÓN, 2008, I:630 d), si éste no coincide con la razón, sí detrás del derecho no hay buenas razones que lo soporten sino sólo la expresión de un poder, entonces, stricto sensu, no estaríamos ante ningún derecho.

\subsection{LA JURISPRUDENCIA COMPARADA}

La apertura a la jurisprudencia de otros países es también una modalidad del «diálogo judicial» que permite la arriba citada Cross-Fertilization of the Legal Systems. Como hemos dicho, actualmente, los órganos jurisdiccionales, principalmente las Cortes Constitucionales y Cortes Supremas han recurrido a la jurisprudencia extranjera para reforzar sus argumentos.

La justificación de lo anterior, para G. Zagrebelsky es expuesta en los siguientes términos:

\footnotetext{
${ }^{14}$ Síntesis del Informe Anual de la Corte IDH de 2010, que se presenta a la Comisión de Asuntos Jurídicos y Políticos de la OEA (Washington, D.C., 18 de marzo de 2011). En: http://goo.gl/iBU9MZ. Fecha de consulta: 1 de octubre de 2013.

${ }^{15}$ El nuevo constitucionalismo, o neoconstitucionalismo es hoy la opción elegida por quienes optan por la apertura a la diversidad de las tradiciones jurídicas; pero el neoconstitucionalismo, ya sea que éste sea entendido como una teoría lo cual por nuestra parte ponemos en tela de duda - o como tendencia del pensamiento que proclama la apertura al pluralismo jurídico-cultural, es una manera distinta de percibir el sentido de lo jurídico. Y como es sabido, toda teoría jurídica, para constituirse como tal, ha de tener, como elemento esencial de su constitución, el explicitación de la teoría de la interpretación conforme por medio de la cual el derecho es comprendido.
} 
Oggi, a differenza del passato, un costituzionalismo exclusivamente nazionale si condannerebbe progresivamente all'impotenza e all'emarginazione de una scienza che perde progresivamente il controllo della propria materia [...]

I compiti della comparazione giuridica odierna si sono arricchiti... Ora, si tratta d'altro e, precisamente, del confronto cooperativo delle esperienze particolari in vista de un orizzonte costituzionale comune nel quale convivano e interagiscano unità e pluralità.

Tra queste esperienze costituzionali comuni, posto relevante occupa quella giurisprudenziale [...] (2012, p. 558-559).

El enriquecimiento de la jurisprudencia nacional, a través de la experiencia jurisprudencial de los demás países de la comunidad internacional, ha tenido un desarrollo lento. Mucho más que el llevado a cabo por los órganos trasnacionales; esto posiblemente se deba al sentimiento de verticalidad y chauvinismo que lleva a desconfiar de aquello que procede de allende las fronteras; esto por un lado, y por el otro, a las políticas de los Estados sobre los que ejercen su jurisdicción, los cuales por diferentes razones no perciben como conveniente ajustar sus políticas públicas, sobre todo en materia de defensa y protección de derechos humanos, a las pautas fijadas por los tratados internacionales ${ }^{16}$.

Sin embargo, un caso paradigmático ha sido el de la Corte Suprema de los Estados Unidos de Norteamérica, en el que como enfatiza Tania Groppi (2011, p. 216), dicho Tribual con su gran historia y autoridad, ha demostrado una actitud from indiferente to hostile, respecto la citación del derecho extranjero. Incluso al interior de la misma Corte Suprema, algunos integrantes se han opuesto a esa visión cerrada y ha comenzado a utilizar el derecho comparado para razonar sus fallos.

No obstante lo anterior, en 1989 el Chief Justice Rehnquist con motivo del 40 aniversario de la Ley Fundamental de Bonn dio un discurso que mostró una postura contraria a la que tradicionalmente había sostenido la propia Corte al establecer lo siguiente:

\begin{abstract}
For nearly a century and a half, courts in the United States exercising the power of judicial review had no precedents to look to save their own, because our courts alone exercised this sort of authority. When many new constitutional courts were created after the Second World War, these courts naturally looked to decisions of the Supreme Court of the United States, among other sources, for developing their own law. But now that constitutional law is solidly ground in so many countries, it is time that the United States courts begin looking to the decision of other constitutional courts to aid in their own deliberative process. The United States courts, and legal scholarship in our country generally, have been somewhat laggard in relying on comparative law and decisions of other countries. But I predict that with so many thriving constitutional courts in the world today... that approach will be changed in the future (REHNQUIST, 1993, p. 241).
\end{abstract}

\footnotetext{
${ }^{16}$ Tal es el caso de México en lo que se refiere a la jerarquía constitucional determinada en el artículo 133 de la Constitución. Los criterios que prevalecen en la SCJN es que prevalece la Constitución sobre los Tratados. Y esto se debe a que la Constitución contiene disposiciones que contradicen Tratados Internacionales, un ejemplo, tal vez el más notorio, es el del arraigo.
}

Revista da Faculdade de Direito - UFPR, Curitiba, vol. 61, n. 1, jan./abr. 2016, p. 9 - 41 
Consecuente con su postura William Rehnquist ha emitido diversas opiniones haciendo uso del derecho comparado ${ }^{17}$. En el mismo sentido lo ha hecho el Justice Anthony M. Kennedy, en el caso Lawrence v. Texas, en el cual acude, para fundamentar su decisión, a la jurisprudencia de la Corte Europea de Derechos Humanos ${ }^{18}$.

Por otra parte, como lo hemos citado, tenemos el caso de la Corte Constitucional de Sudáfrica, que en virtud de disposición expresa en su Constitución (artículo 39) se encuentra obligada a considerar el derecho extranjero.

En México, la experiencia ha sido exigua, como ejemplo citaremos el criterio jurisprudencial P.LXVI/2009 (mismo que se puede apreciar en la Novena Época del Semanario Judicial de la Federación y su Gaceta, Tomo XXX, p. 7, de diciembre de 2009), de cuyo contenido se desprende la aplicación de la doctrina y jurisprudencia comparada ${ }^{19}$ relativo al «derecho al libre desarrollo de la personalidad». En esta ejecutoria, que dicho sea de paso, ha provocado opiniones encontradas en la comunidad jurídica nacional, se tomó como referencia de fundamentación los criterios del Tribunal Europeo de Derechos Humanos; los de la Sala Civil del Tribunal Supremo de España; los de la Corte Constitucional Colombiana; y los del Tribunal Constitucional de Perú, entre otros.

En el «derecho al libre desarrollo de la personalidad» se aprecia, con meridiana claridad, la influencia del Cross-Fertilization of the Legal Systems, la cual trajo como consecuencia la protección de un derecho que no se encuentra contendido de manera textual en la Constitución Mexicana, sino sólo de manera implícita; es decir, en el horizonte del texto. Y con apoyo del

\footnotetext{
${ }^{17}$ Véase las opiniones en Raines v. Byrd, 521 U.S. 811,828 (1997) y Washington v. Glucksberg, U.S. 702, 710, 718 n. 16, 785-787 (1997).

${ }^{18}$ Dicho desarrollo jurisprudencial no ha sido pacífico ya que como lo establece Tania Groppi, "hay quienes condenan indiscriminadamente cualquier referencia al derecho extranjero, de prescindir del uso que se le hace. Esta es la posición del juez Scalia, expresada tanto en las opiniones como en sus intervenciones extrajudiciales (famoso es su debate con el juez Breyer, quien se ubica en una posición opuesta, en la American University en enero de 2005). Este punto de vista ha encontrado un respaldo político: en marzo de 2004 en la House of Representatives, y en 2005 en el Senado, los republicanos intentaron aprobar una resolución que prohibiera tales citaciones, e incluso fue también el punto central de los hearings de ratificación del Chief Justice Roberts y del juez Alito, cuando un senador inclusive propuso que la citación del derecho extranjero fuera considerada un delito susceptible de impeachment (2013, p. 216).

${ }^{19}$ Tesis: P. LXVI/2009, emitida por el Pleno de la Suprema Corte de Justicia de la Nación, visible en la Novena Época del Semanario Judicial de la Federación y su Gaceta, Tomo XXX, p. 7, de diciembre de 2009, que establece: DERECHO AL LIBRE DESARROLLO DE LA PERSONALIDAD. ASPECTOS QUE COMPRENDE. De la dignidad humana, como derecho fundamental superior reconocido por el orden jurídico mexicano, deriva, entre otros derechos personalísimos, el de todo individuo a elegir en forma libre y autónoma su proyecto de vida. Así, acorde a la doctrina y jurisprudencia comparadas, tal derecho es el reconocimiento del Estado sobre la facultad natural de toda persona a ser individualmente como quiere ser, sin coacción ni controles injustificados, con el fin de cumplir las metas u objetivos que se ha fijado, de acuerdo con sus valores, ideas, expectativas, gustos, etcétera. Por tanto, el libre desarrollo de la personalidad comprende, entre otras expresiones, la libertad de contraer matrimonio o no hacerlo; de procrear hijos y cuántos, o bien, decidir no tenerlos; de escoger su apariencia personal; su profesión o actividad laboral, así como la libre opción sexual, en tanto que todos estos aspectos son parte de la forma en que una persona desea proyectarse y vivir su vida y que, por tanto, sólo a ella corresponde decidir autónomamente.
} 
enfoque iuspositivismo analítico, entrelazado con la jurisprudencia sociológica y la jurisprudencia comparada, la SCJN reforzó la argumentación de su decisión para el reconocimiento del referido derecho.

Coincidimos con G. Zagrebelsky cuando dice que:

Il rilievo per le giurisprudenze nazionali delle giurisprudenze straniere o sopranazionali non presuppone dunque affatto l'umilazione delle costituzioni nazionali. Si sta parlando non di un cavallo di Troia per affermare una «dittatura universalistica dei diritti», ma di uno strumento per intendere le nostre proprie costituzioni nazionali (ZABREBELSKY, 2012, p. 561).

Pues, desde nuestro punto de vista, el Cross-Fertilization of the Legal Systems, o sincretismo jurídico cultural que se produce a través de un diálogo jurídico-cultural en el mundo globalizado de hoy, no es intervencionismo o dominación de los países del centro a los de la periferia a través de las tradiciones jurídicas, sino una mejor forma de comprensión del derecho propio, por medio de la comprensión del derecho de otros países, y el que emerge de los organismos supranacionales que protegen derechos humanos.

\section{LOS PRESUPUESTOS TEÓRICOS DEL DIÁLOGO HERMENÉUTICO}

El concepto de otredad o alteridad, que parece encontrarse en la anterior cita de G. Zagrebelsky, se refiere al otro, o a los otros. Otredad es el otro (o los otros) porque son diferentes a mí, o a nosotros. Es la diferencia que yo tengo (o tenemos con el otro), o con los otros; pero a la vez es concomitancia, en la cual se finca tanto la universalidad como la individualización. Por eso, de acuerdo a uno de los presupuestos de la hermenéutica filosófica, la comprensión (verstehen) de uno mismo precisa del otro; esto es, de la comprensión del otro ${ }^{20}$, lo cual se logra por medio de un diálogo racional. Comprendiendo al otro nos comprendemos a nosotros mismos; y a la vez, comprendiéndonos a nosotros mismos, comprendemos al otro.

La hermenéutica es esencialmente diálogo, diálogo racional. Es significativo que en el capítulo 12 de Verdad y método: El lenguaje como medio de la experiencia hermenéutica, Gadamer inscribe el siguiente epígrafe de F. Schleiermacher: «Todo lo que hay que presuponer en la

\footnotetext{
${ }^{20}$ G. H. Gadamer, dice al respecto: "El que quiere comprender no puede entregarse desde el principio al azar de sus propias opiniones previas e ignorar lo más obstinada y consecuentemente posible la opinión del texto...hasta que este finalmente ya no pueda ser ignorado y dé al traste con su supuesta comprensión. El que quiere comprender un texto tiene que estar en principio dispuesto de dejarse decir algo por él. Una conciencia formada hermenéuticamente tiene que mostrarse receptiva desde el principio para la alteridad del texto. Pero esta receptividad no presupone ni neutralidad ante las cosas ni tampoco autocancelación, sino que incluye una matizada incorporación de las propias opiniones previas y prejuicios” (GADAMER, 2005, p. 335-336).
} 
hermenéutica es únicamente lenguaje» (GADAMER, 2005, p. 460). En este mismo capítulo, Gadamer plantea la tesis de que la conversación es, por antonomasia, la mejor forma del diálogo, algo que el mismo Schleiermacher también aborda cuando sostiene que ésta (la conversación) se da entre espíritus afines. "La verdadera conversación no es nunca la que uno habría querido llevar. Al contrario, en general sería más correcto decir que «entramos» en una conversación, cuando no que nos «enredamos» en ella” (GADAMER, 2005, p. 461).

Un diálogo hermenéutico en cualquiera de sus formas - aunque a decir de Gadamer la conversación es la menos difícil - es, entonces, aquel en el que, a la pregunta, con un determinado sentido, le viene aparejada una respuesta, también con un sentido que conduce a una nueva pregunta; y así a través de un proceso de preguntas y respuestas con una determinada orientación, al agotarse las preguntas se llega a un acuerdo de sentido sobre algo. En el ámbito de la hermenéutica filosófica-jurídica, dicho esto con mayor propiedad, se llega al des-ocultamiento de una verdad jurídica.

Preguntar en Heidegger es abrir caminos, y para Gadamer preguntar y comprender es lo que da a la experiencia hermenéutica su verdadera dimensión. El que quiere comprender puede, desde luego, dejar en suspenso la verdad de su referencia inmediata de la cosa a la referencia de sentido como tal, y considerar ésta no como verdad sino simplemente como algo con sentido que proviene de una interpretación correcta.

A partir de la aceptación de que en toda «comprensión» opera un compromiso, tesis que contradice a los teóricos de la Ilustración para quienes el punto de partida del quehacer científico es deshacerse de los prejuicios, Gadamer postula que "no está en cuestión lo que hacemos ni lo que deberíamos de hacer, sino lo que ocurre con nosotros por encima de nuestro querer y hacer” (GADAMER, 2005, p. 10); y la tarea hermenéutica, cuya función esencial es lograr la «comprensión» de algo, consiste en entrar en diálogo racional con uno o varios interlocutores, o con un texto escrito.

En efecto, la hermenéutica filosófica reivindica los prejuicios que habían sido denostados por la Ilustración. A la comprensión de un texto oral o escrito se llega poniendo en movimiento los prejuicios del intérprete; no hay comprensión sin anticipación de sentido, y es en el proceso de un constante proyectar donde los prejuicios se confirman, en cuyo caso dejan de ser prejuicios y se convierten en juicios, o bien, en el supuesto de que éstos no puedan ser confirmados, se tienen que abandonar.

Esto es así porque la posibilidad de comprensión, en Gadamer - uno de los principales fundadores de la hermenéutica filosófica -, se funda en nexos de sentido con las cosas del mundo, 
que son descubiertos por el intérprete por medio de una movilidad horizóntica, tradición jurídica, en nuestro caso. Horizonte, dice Gadamer, es ámbito de visión, o percepción, perspectiva de sentido que se encuentra en los textos escritos y orales, o, en otras palabras, es lo que, en un texto normativo de naturaleza jurídica, por ejemplo, se encuentra presupuesto, no textual o explicitado.

Resulta formidable y esperanzador, entonces, que la idea de que la «comprensión» (verstehen) del derecho interno, o de nuestra Constitución, se comprende desde la comprensión de los otros sistemas jurídicos, tesis sostenida por G. Zagrebelsky, sea uno de los ejes principales sobre el que comienza a girar el debate del diálogo judicial, el cual, para nosotros, se daría un salto cualitativo si dicho diálogo se entendiera como diálogo hermenéutico.

Para que se produzca el diálogo hermenéutico, de acuerdo a Gadamer, no se precisa que la situación hermenéutica, sea del texto o de los actores de una conversación oral, sea idéntica, sino más bien que exista entre los participantes del diálogo - judicial en nuestro caso -, un asunto común que una a las partes.

En el caso de los textos se tratan de «manifestaciones vitales fijadas duraderamente» que deben ser entendidas, lo que significa que una parte de la conversación hermenéutica, el texto, solo puede llegar a hablar a través de la otra parte, del intérprete. Solo por él se convierten los signos escritos de nuevo en sentido. Al mismo tiempo, y en virtud de esta reconversión a la comprensión, accede al lenguaje el asunto mismo del que habla el texto. Igual que las conversaciones reales, es el asunto común el que une entre sí a las partes, en este caso al texto y al intérprete [...] En consecuencia está plenamente justificado hablar de una conversación hermenéutica (2005, p. 466).

A lo que aquí añadimos que, ese asunto común, tendría que tener también en los participantes del diálogo un «designio» común; es decir, se necesitaría que en el pensamiento (o propósito del entendimiento) aceptado por la voluntad de los participantes del diálogo judicial, lo que en el caso del diálogo judicial no podría ser otro que la búsqueda de la realización de la justicia. He ahí, entonces, nuestra posición con respecto al diálogo judicial, como diálogo hermenéutico, el cual no en todos los casos es posible que se alcance porque, si bien puede haber un asunto que una a los participantes del diálogo en la comunidad internacional, ni siquiera tratándose de un tema como el de la defensa y el desarrollo de los derechos humanos podría encontrarse entre los participantes del diálogo un mismo «designio» común, condición sine qua non para que se realice el diálogo hermenéutico, porque, en este caso, habría una coincidencia entre Derecho y razón. Mas el problema sería la falta de coincidencia entre los dialogantes, pues habría casos en que otros factores tuvieran mayor peso en las políticas públicas, que la defensa misma de los derechos humanos, lo que trae como consecuencia que el diálogo hermenéutico no pocas veces se interrumpa. 
Por lo mismo, ¿qué pasa cuando el diálogo judicial no conduce al des-ocultamiento ${ }^{21}$ de una verdad jurídica, lo que ciertamente ocurre no con poca frecuencia? En estos casos el diálogo judicial no es racional. No posee la estructura de un diálogo hermenéutico. Y, por tanto, ello en razón de que no siempre en las prácticas judiciales los tribunales orientan sus decisiones a la luz del diálogo hermenéutico. Por lo general, las decisiones de los tribunales solo recurren a las fuentes formales del derecho (la ley y los precedentes), la doctrina usualmente no es tomada en cuenta ${ }^{22}$; esto por un lado, y por el otro, en la interpretación que se hace de la ley y la jurisprudencia ${ }^{23}$ se evade el problema de la justificación interna, es decir, se omite dar razones epistemológicas u ontológicas que condujeron a la decisión tomada en el proceso de interpretación, resultando de lo anterior una no coincidencia entre el derecho y la razón.

Desde antiguo, la hermenéutica se ocupa del problema de la verdad en el ámbito de la interpretación. Y para la nueva hermenéutica, conocida también como hermenéutica filosófica, esta disciplina se ocupa del problema de la verdad en el ámbito de la interpretación. O de manera más precisa, del fenómeno de la comprensión y la correcta interpretación de lo comprendido (GADAMER, 2005, p. 23); las verdades que surgen de la razón hermenéutica, no son verdades bivalentes que se comprueban por medio de la correspondencia de un enunciado con una cosa $\mathrm{u}$ objeto, sino más bien verdades polivalentes que emerge de una interpretación correcta y muestran la congruencia del pensar en pro de un determinado designio, en el caso de los jueces, por ejemplo, el designio sería la búsqueda de la realización de la justicia, algo a lo que ya nos hemos referido.

Ya en la tradición de la vieja hermenéutica, la cual en los primeros años del siglo XIX es apartada de la teología para abordársele filosóficamente por Schleiermacher - y en la segunda mitad del siglo XX, con Heidegger, adquiere un giro ontológico -, la realización de la comprensión no es posible sin la interpretación.

La interpretación, para Gadamer, "no es un acto complementario y posterior a la «comprensión», sino que comprender es siempre interpretar, y en consecuencia, la interpretación es la forma explícita de la comprensión” (2005, p. 378). En el caso de la interpretación jurídica, esto significa que el sentido que trata de comprender el intérprete en el texto de la ley (con relación a una situación específica en la que se desenvuelve el caso en estudio), sólo se concreta y completa por medio de la interpretación (GADAMER, 2005, p. 405).

\footnotetext{
${ }^{21}$ El problema de la verdad jurídica, desde una perspectiva no positivista, sino más bien fundada en la hermenéutica espiritual científica, estimamos que es algo que aún está por realizarse; ello a pesar de los avances dados por los juristas, entre ellos Alexy (1997, p. 111-3), apoyándose en Habermas, a la crítica de la verdad como correspondencia.

${ }^{22}$ A no ser la que forma parte del paradigma dominante, la cual nos predetermina.

${ }^{23}$ La jurisprudencia también tiene que ser interpretada.
} 
La comprensión, desde F. Schleiermacher y posteriormente desarrollado por Gadamer, es un acuerdo de sentido sobre algo, al cual se llega por medio de un diálogo racional al que ya nos hemos referido. Ahora bien, el diálogo es racional, si y sólo si, a cada pregunta con dirección y sentido, le viene de inmediato una respuesta, también con dirección y sentido. El diálogo racional, el cual se remonta a Platón, sólo llega a su fin en el momento en que los interlocutores logran el acuerdo de sentido que se busca, o cuando alguno de los interlocutores (o los dos) lo abandonan; pero si se abandona el diálogo hermenéutico, por renunciar a la verdad que surge del diálogo - la única verdad socialmente aceptada, incluso en las comunidades científicas de las ciencias naturales, en razón de que no hay verdad que no surja de un proceso dialógico -, con ello queda al desnudo un poder, por carecer de legitimidad ontológica o epistemológica. En este supuesto el derecho, como hemos dicho, se muestra sólo como una expresión del poder; pero no del saber fundado en la razón hermenéutica.

El diálogo se da de muchos modos, sin que necesariamente haya cercanía entre los interlocutores ni una relación estrecha entre preguntas y respuestas; y no indefectiblemente es racional. Se produce en las comunidades científicas, en el congreso de los diputados, en los medios de comunicación, etc., y no inevitablemente es vinculante. En él pueden participar no dos interlocutores sino un número indeterminado, como en el caso del diálogo democrático en el que, además, el acuerdo de sentido alcanzado no es vinculante y no necesariamente concuerda con una determinada razón socialmente aceptada; pero en el caso del diálogo judicial, además de ser un diálogo institucional tiene como característica esencial la vinculatoriedad y que, el sentido que se trata de alcanzar, es un sentido autorizado definido y final. Pero no obstante su aspecto vinculante, no en todos los casos trae consigo una coacción, por ejemplo, el caso del diálogo judicial entre países relacionado a la defensa de los derechos humanos es uno de ellos.

Hasta aquí nuestras consideraciones teóricas sobre el diálogo judicial como diálogo hermenéutico, fundadas en la hermenéutica filosófica; ahora veremos, en el siguiente punto, cómo en el caso concreto de la SCJN, por medio de una sobreinterpretación (ante la cual la comunidad jurídica o únicamente guarda silencio, o bien, no realiza una construcción argumentativa sólida y efectiva), se desacata lo estipulado en la reforma constitucional de 2011, en el sentido de que "las normas relativas a los derechos humanos se interpretarán de conformidad con esta Constitución y con los tratados internacionales de la materia favoreciendo en todo tiempo a las personas la protección más amplia”.

Lo que prueba, desde nuestro punto de vista, que para la protección de los derechos humanos no es suficiente un bloque de constitucionalidad, de lo que tanto se ha hablado desde que 
se dio a conocer la reforma constitucional citada. Tan importante como el bloque de constitucionalidad es también el dominio de los diferentes paradigmas interpretativos, sin lo cual no es posible refutar con argumentos sólidos los criterios de la SCJN.

\section{LA RUPTURA DEL DIÁLOGO JUDICIAL EN LA JURISPRUDENCIA DE LA SCJN}

Caso paradigmático de la ruptura del diálogo judicial, por medio de los criterios emitidos por la SCJN, se encuentra en la resolución a la contradicción de tesis 293/2011, de la cual se deriva la jurisprudencia P./J. 20/2014 (10a.) ${ }^{24}$, en la que el máximo tribunal de México establece que si bien las normas de derechos humanos, independientemente de su fuente, no se relacionan en términos jerárquicos como consecuencia del contenido del párrafo primero del artículo 1 constitucional, “cuando en la Constitución haya una restricción expresa al ejercicio de los derechos humanos, se deberá estar a lo que indica la norma constitucional”, ya que a juicio de dicho órgano jurisdiccional "el principio que le brinda supremacía comporta el encumbramiento de la Constitución como norma fundamental del orden jurídico mexicano, lo que a su vez implica que el resto de las normas jurídicas deben ser acordes con la misma”.

Sobre esta tesis sobresaliente de la SCJN, y otras en el mismo sentido, Fernando Silva García, hace el siguiente comentario:

1) Los derechos humanos reconocidos en la Constitución y en los tratados internacionales adoptados por el Estado mexicano conforman el parámetro de validez de toda la actuación pública.

2) Los posibles conflictos y antinomias entre derechos humanos reconocidos en la Constitución y en los tratados internacionales adoptados por el Estado mexicano deben resolverse de acuerdo con el principio de la norma más favorable a la persona humana (principio pro homine) y no en términos jerárquicos; con una excepción; cuando en la Constitución haya una restricción expresa al ejercicio de los derechos humanos se deberá estar a lo que indica la norma constitucional.

3) Asimismo, por una votación sorpresiva de seis votos contra cinco, el Pleno de la SCJN resolvió que la jurisprudencia de la Corte IDH tiene carácter vinculante (SILVA GARGÍA, 2014, p. 257).

\footnotetext{
${ }^{24}$ Véase en la Décima Época de la Gaceta del Semanario Judicial de la Federación, Libro 5, Tomo I, abril de 2014, página 202, Registro IUS: 2006224.
} 
Desde nuestro punto de vista, las implicaciones en el diálogo judicial de lo resuelto en los puntos 2 y 3 antes señalados, expresan una relevancia negativa, ya que, como dejamos dicho al final del punto anterior, por medio de una «sobre-interpretación» del máximo tribunal se desobedece un mandato constitucional. Esto se aprecia de manera clara en los criterios jurisprudenciales que le sucedieron a la tesis de la SCJN antes transcrita, los cuales más adelante reproducimos para que se contraste con nuestro punto de vista. Hay «sobre-interpretación», cuando la opinión que el tribunal supremo hace valer en una tesis jurisprudencial que emite trasgrede (o se aparte del fin u objetivo) de lo «proyectado» por el legislador en la «comprensión» que logró alcanzar en el contenido de la ley (o enunciados normativos) que dictó.

Ahora bien, es verdad que la teoría más consistente de la interpretación, en la cual nos inscribimos, sostiene que la interpretación no es algo que se logre por medio de un proceso deductivo o de subsunción, sino que interpretar es concretar y completar lo que ordena una ley o enunciado normativo. Pero no es jurídico ni racional que la interpretación que se haga de la ley se aparte del «designio» que fue proyectado por el legislador, porque en este supuesto no estaríamos propiamente ante una interpretación sino más bien una «sobre-interpretación».

Nuestro punto de vista se apoya en la tesis sostenida por uno de los más grandes pensadores del siglo XX, como lo es $\mathrm{M}$. Heidegger, para quien, desde la perspectiva de la ontologización de la hermenéutica, "la interpretación no es tomar conocimiento de lo comprendido, sino el desarrollo de las posibilidades proyectadas en el comprender” (HEIDEGGER, 2010, p. 166). $\mathrm{Y}$ es el caso que, en el tema que nos ocupa, la jurisprudencia de la SCJN se aparta de las posibilidades proyectadas por el legislador en el artículo 1 de la Constitución Política de los Estados Unidos Mexicanos, principalmente en el segundo y tercer párrafo, que aquí reproducimos de manera textual:

Artículo 1. En los Estados Unidos Mexicanos todas las personas gozarán de los derechos humanos reconocidos en esta Constitución y en los tratados internacionales de los que el Estado Mexicano sea parte, así como de las garantías para su protección, cuyo ejercicio no podrá restringirse ni suspenderse, salvo en los casos y bajo las condiciones que esta Constitución establece.

Las normas relativas a los derechos humanos se interpretarán de conformidad con esta Constitución y con los tratados internacionales de la materia favoreciendo en todo tiempo a las personas la protección más amplia.

Todas las autoridades, en el ámbito de sus competencias, tienen la obligación de promover, respetar, proteger y garantizar los derechos humanos de conformidad con los principios de universalidad, interdependencia, indivisibilidad y progresividad. En consecuencia, el Estado deberá prevenir, investigar, sancionar y reparar las violaciones a los derechos humanos, en los términos que establezca la ley.

Está prohibida la esclavitud en los Estados Unidos Mexicanos. Los esclavos del extranjero que entren al territorio nacional alcanzarán, por este solo hecho, su libertad y la protección de las leyes. 
Queda prohibida toda discriminación motivada por origen étnico o nacional, el género, la edad, las discapacidades, la condición social, las condiciones de salud, la religión, las opiniones, las preferencias sexuales, el estado civil o cualquier otra que atente contra la dignidad humana y tenga por objeto anular o menoscabar los derechos y libertades de las personas.

Pues bien, por nuestra parte, con relación a la supremacía de las restricciones constitucionales expresas (respecto a los derechos humanos de fuente internacional), sostenemos que se configura la imposibilidad del diálogo desde el momento en que la SCJN establece una prohibición procesal consistente en solicitar la preferencia de los citados derechos y su desarrollo a través de la jurisprudencia interamericana, tal como se desprende de la jurisprudencia 2a./J. 119/2014 (10a) $)^{25}$, en la cual se resolvió que:

Los agravios en los que se pretenda la desaplicación de una restricción, prohibición, limitación o excepción constitucional con apoyo en una disposición de carácter convencional resultan inoperantes, al tratarse aquéllas de una expresión del Constituyente que prevalece, en todo caso y condición, frente a cualquier otra norma derivada, con independencia de que ésta tenga el mismo nivel que la Constitución Federal.

La tesis referida tiene como consecuencia inevitable que los jueces nacionales declaren inoperante cualquier argumento que implique la inaplicación de una restricción, prohibición limitación o excepción constitucional, con apoyo en una disposición de carácter convencional. Esto implica, a su vez, que el juzgador se encuentra siquiera impedido a acudir al desarrollo jurisprudencial de dicha disposición de carácter convencional; lo que evidentemente obstaculizará el diálogo judicial, y, con, ello, el diálogo hermenéutico.

Por otro lado, al resolver la contradicción de tesis 293/2011, la SCJN determinó que la jurisprudencia de la Corte Interamericana de Derechos Humanos (CIDH) tiene carácter vinculante, lo anterior se puede apreciar en la tesis P./J. 21/2014 (10a) ${ }^{26}$, misma en la que se concluyó que

los criterios jurisprudenciales de la Corte Interamericana de Derechos Humanos, con independencia de que el Estado Mexicano haya sido parte en el litigio ante dicho tribunal, resultan vinculantes para los Jueces nacionales al constituir una extensión de la Convención Americana sobre Derechos Humanos, toda vez que en dichos criterios se determina el contenido de los derechos humanos establecidos en ese tratado.

Ahora bien, aunque en principio, la tesis referida parece tener un resultado positivo, al dar carácter vinculante a los criterios de la Corte Interamericana de Derechos Humanos y estableciendo directrices para su aplicación por los jueces nacionales que redundan en un verdadero diálogo judicial, los efectos de la tesis relativa a las restricciones constitucionales y su superioridad en

\footnotetext{
${ }^{25}$ Décima Época de la Gaceta del Semanario Judicial de la Federación, Libro 12, Tomo I, noviembre de 2014, página 768, Registro IUS: 2007932.

${ }^{26}$ Décima Época de la Gaceta del Semanario Judicial de la Federación, Libro 5, Tomo I, abril de 2014, página 204, Registro IUS: 2006225.
} 
relación con los derechos convencionales surte sus efectos e impacta también en la aplicación de la jurisprudencia de la Corte Interamericana de Derechos Humanos y en consecuencia en el diálogo judicial, tal como se desprende de la tesis P. XVI/2015 (10a.) ${ }^{27}$ en la cual se determina que aun cuando se haya reconocido el carácter vinculante de la jurisprudencia de la CIDH, "si alguno de los deberes del fallo implica desconocer una restricción constitucional”, debe prevalecer dicha restricción, tomando como base la tesis P./J. 20/2014 (10a.) arriba descrita.

Como se aprecia de lo antes expuesto, la SCJN vuelve al discurso de la prevalencia de las restricciones constitucionales, pero ahora en relación con la jurisprudencia de la Corte IDH, aun cuando se trate de un fallo en los que el Estado Mexicano sea parte, a este respecto es pertinente citar el contenido del Expediente Varios 1396/2011 ${ }^{28}$, donde se resuelve lo siguiente:

Por otro lado, cabe precisar que este Tribunal Pleno ha determinado que el resto de la jurisprudencia de la Corte Interamericana que deriva de las sentencias en donde el Estado Mexicano no figura como parte, también tendrá el carácter de criterio vinculante cuando resulte más favorable en términos del principio pro persona contenido en el artículo 1o. constitucional, toda vez que éste sienta las bases para una interpretación mínima respecto a un derecho particular. Debiéndose precisar que, en estos casos, no debe entenderse el carácter vinculante de los criterios interamericanos en un sentido fuerte, sino como una vinculación a los operadores jurídicos a observar en sus resoluciones un estándar mínimo, que bien podría ser el internacional o el nacional, dependiendo cuál resulte más favorable a las personas.

$[\ldots]$

SEXTO. Obligaciones concretas que debe realizar el Poder Judicial. Como una cuestión previa al pronunciamiento de vinculación de este Poder con los asuntos materia de cumplimiento, se hace necesario precisar, en forma concreta, el alcance de las obligaciones de este Alto Tribunal.

Para ello, se parte del hecho ya referido de que la jurisdicción de la Corte Interamericana de Derechos Humanos es aceptada por el Estado Mexicano y que, en esa medida, en tanto se esté frente al incumplimiento de obligaciones expresamente contraídas por dicho signante, no corresponde, entonces, a esta Suprema Corte de Justicia de la Nación, analizar, revisar, calificar o decidir, si una sentencia dictada por este organismo internacional es correcta o no, lo que debe entenderse en forma unímoda y dogmática, ya que la competencia de este Tribunal Constitucional del Estado Mexicano, como garante de la supremacía constitucional, descansa ontológica e inminentemente en su actuación, de acuerdo con lo dispuesto en el artículo 133 de nuestra Carta Magna.

Por tanto, para establecer y concretar las obligaciones que debe cumplir el Poder Judicial de la Federación, en atención a las sentencias internacionales, se estima adecuado analizar siempre la correspondencia que debe existir entre los derechos humanos que estimó vulnerados la Corte Interamericana de Derechos Humanos, con aquellos que se encuentran dispuestos en la Constitución Política de los Estados Unidos Mexicanos, o en los tratados que el Estado Mexicano celebre y que, por tanto, se comprometió a respetar, en el entendido de que, si alguno de los deberes del fallo implica el desconocimiento de una restricción constitucional, deberá prevalecer ésta, en términos de lo determinado por el Pleno de la Suprema Corte de Justicia de la Nación, al resolver la contradicción de tesis

${ }^{27}$ Décima Época de la Gaceta del Semanario Judicial de la Federación, Libro 22, Tomo I, septiembre de 2015, página 237, Registro IUS: 2010000.

${ }^{28}$ Décima Época de la Gaceta del Semanario Judicial de la Federación, Libro 22, Tomo I, septiembre de 2015, página 127, Registro IUS: 25836. 
293/2011, en sesión de tres de septiembre de dos mil trece, y que originó la jurisprudencia P./J. 20/2014 (10a.), intitulada: "DERECHOS HUMANOS CONTENIDOS EN LA CONSTITUCIÓN Y EN LOS TRATADOS INTERNACIONALES. CONSTITUYEN EL PARÁMETRO DE CONTROL DE REGULARIDAD CONSTITUCIONAL, PERO CUANDO EN LA CONSTITUCIÓN HAYA UNA RESTRICCIÓN EXPRESA AL EJERCICIO DE AQUÉLLOS, SE DEBE ESTAR A LO QUE ESTABLECE EL TEXTO CONSTITUCIONAL.” (4)

Lo anterior es coincidente con la reforma al artículo 1 de la Constitución Política de los Estados Unidos Mexicanos, publicada el diez de junio de dos mil once, mediante la cual se dio pleno reconocimiento del goce que toda persona tiene en nuestro país, de los derechos humanos dispuestos en nuestro Máximo Ordenamiento y en los tratados internacionales celebrados por la nación mexicana que estén de acuerdo con éste y de los que la nación mexicana sea parte.

Como se podrá observar, de conformidad con los argumentos expuestos a lo largo de este estudio, centrado en los supuestos teóricos de la hermenéutica filosófica - hasta ahora, desde nuestro punto de vista, el pensamiento que más ha hecho evolucionar el canon hermenéutico - la SCJN, por medio del establecimiento de restricciones constitucionales, se aparta de sus propios criterios para impedir la invocación de los jueces de los criterios de la CIDH.

Lo anterior significa que, el juez nacional, ante estas limitaciones constitucionales que la SCJN le impone a través de sus criterios «sobre-interpretativos», se encuentra impedido para acudir a la jurisprudencia de las jurisdicciones internacionales, con el propósito de buscar el criterio más favorable a para persona.

\section{CONCLUSIONES}

Bajo las directrices de la hermenéutica filosófica, que hay que acercar a la praxis jurídica, apuntamos como primera conclusión que la principal exigencia que se tendría que cumplir para la realización del diálogo judicial hermenéutico, es que las partes, que en él intervienen, se reconozcan como iguales, en cuanto a capacidades de comprensión, argumentación y de interpretación.

Ahora bien, como se ha mostrado con algunas tesis de la SCJN, en las jurisdicciones internas que operan bajo un mayor acercamiento al sistema de control constitucional concentrado, como es el caso de México, dicho diálogo es mínimo. Lo esperable sería que, sobre todo en materia de derechos humanos y asuntos que tienen que ver con la protección del medio ambiente, se intensifique el diálogo judicial entre jurisdicciones constitucionales y los organismos supranacionales, y, a la vez, se incremente también las investigaciones desarrolladas desde la perspectiva de la crítica jurídica (sobre todo las decisiones judiciales), con lo cual sería posible generar condiciones que obliguen a la Corte y a las políticas de Estado, a cambiar de rumbo, a abrirse a la razón hermenéutica, venga de donde venga. Pues, como dejamos dicho, el diálogo 
jurídico-cultural en el mundo globalizado no es en realidad intrusismo, sino un nuevo enfoque que ayuda a la comprensión del derecho interno.

Por lo mismo, los operadores jurídicos tendrían que comprender, que la movilidad horizontica, allende las fronteras, no vulnera la soberanía ni tiene porqué lastimar sentimientos nacionales. Pues, tanto en las ciencias del espíritu como en las ciencias naturales, no hay verdad que no surja de un diálogo racional, el cual carece de fronteras. Así que, insistimos, sin alteridad no hay posibilidad de desarrollo de la ciencia; sin alteridad, se cancela la posibilidad de una mejor comprensión del derecho propio, por medio de la comprensión del derecho de otros países y el que se produce por los organismos supranacionales que protegen derechos humanos.

Por último: no en todos los casos en que la SCJN cambia de criterio es algo que tenga que ver con «sobre-interpretaciones», producto de actitudes tiránicas, sino porque, aun desde las teorías de la interpretación desarrolladas por las diversas escuelas positivistas (en las que también es posible el logro de la comprensión, aunque de manera tortuosa y evadiendo el compromiso, por medio del método), la situación hermenéutica sobre la que se resuelve nunca es la misma. Pero, desde la óptica de la hermenéutica filosófica, abandonar un criterio por otro, debido a la situación hermenéutica, la cual determina el sentido que se busca por medio de la interpretación, nunca es para vulnerar derechos, sino para cumplir a cabalidad con el «designio» del máximo tribunal y de todos los juzgadores: la realización de la justicia.

\section{BIBLIOGRAFÍA}

AARNIO, Aulis. On Legal Reasoning. Turku: Annales Universitatis Turkuensis, 1977.

ALEXY, Robert. Teoría de la argumentación jurídica (trad. Manuel Atienza e Isabel Espejo). Madrid, Centro de Estudios Constitucionales, 1997.

BAZAN, Víctor. Control de convencionalidad, puentes jurisdiccionales dialógicas y protección de los derechos humanos. En: Revista Iberoamericana de Derecho Procesal Constitucional, No. 18, julio-diciembre, 2012.

BURGORGUE-LARSEN, Laurence. La formación de un derecho europeo a través del diálogo judicial. En: SAIZ ARNAIZ, Alejandro; FERRER MAC-GREGOR, Eduardo (Ed.). Control de convencionalidad, interpretación conforme y diálogo jurisprudencial. México: Porrúa/Universidad Nacional Autónoma de México, 2012.

BUSTOS GISBERT, Rafael. Pluralismo constitucional y diálogo jurisprudencial. México: Editorial Porrúa/Instituto Mexicano de Derecho Procesal Constitucional, 2012. 
CABRA APALATEGUI, José Manuel. Argumentación jurídica y Racionalidad en A. Aarnio. Madrid: Instituto de Derechos Humanos "Bartolomé de las Casas", Universidad Carlos III de Madrid, 2000.

CARBONELL, Miguel. Constitución, reforma constitucional y fuentes del derecho en México. México: Editorial Porrúa-UNAM, 2008.

FERRAJOLI, Luigi. Derechos y garantías. La ley del más débil. Séptima edición (trad. de Perfecto Andrés Ibáñez y Andrea Greppi). Madrid: Trotta, 2010.

FERRAJOLI, Luigi. Más allá de la soberanía y la ciudadanía: Un constitucionalismo global. En: CARBONELL, Miguel; VÁZQUEZ, Rodolfo (Comp.). Estado constitucional y globalización. Segunda edición. México: Editorial Porrúa/UNAM, 2003.

FERRER MAC-GREGOR, Eduardo. El nuevo paradigma para el juez mexicano. En: CARBONELL, Miguel; SALAZAR, Pedro (Ed.). La reforma constitucional de Derechos Humanos. Un nuevo paradigma. México: Editorial Porrúa/UNAM, 2012.

GADAMER, Hans-Georg. Verdad y método (trad. de Ana Agud Aparicio y Rafael Agapito). España: Ediciones Sígueme, Salamanca, 2005.

GARCÍA CALVO, Manuel. Los fundamentos del método jurídico: una revisión crítica. España: Tecnos, 1994.

GROPPI, Tania. ¿Bottom up globalization? El uso de precedentes extranjeros por parte de las Cortes Constitucionales. En: Revista Iberoamericana de Derecho Procesal Constitucional, No. 16, julio-diciembre, 2011.

HÄBERLE, Peter. Pluralismo y Constitución. Estudios de Teoría Constitucional de la sociedad abierta (trad. de Emilio Mikunda-Franco). Madrid, Tecnos, 2002.

HABERMAS, Jürgen. El discurso filosófico de la modernidad (trad. Manuel Jiménez Redondo). España: Taurus, 1993.

. Modernidad: un proyecto incompleto. En: CASULLO, Nicolas. El debate modernidadposmodernidad. Buenos Aires: Retórica Ediciones, 2004.

HART, Herbert Lionel Adolphus. El concepto de derecho (trad. Genaro R. Corrió). Buenos Aires: Abeledo-Perrot, 1992.

HEIDEGGER, Martin. Seminarios de Zollikon (trad. Ángel Xolocotzi Yánez). Michoacán, México: Red Utopía, A.C., Jitanjáfora Morelia Editorial, 2007.

. Ser y tiempo (trad. de José Gaos). México, D.F.: FCE, 2010.

JACOBS, Francis G. Judicial Dialogue and the Cross-Fertilization of Legal Systems: The European Court of Justice. En: Texas International Law Journal, No. 38, 2003.

KELSEN, Hans. Teoría pura del derecho (trad. Roberto Vernengo). México, D.F.: UNAM, 1982. 
KERN, Lucian; MÜLLER Hans Peter. La justicia: ¿Discurso o mercado? Los nuevos enfoques de la teoría contractualista (trad. Jorge M. Seña). Barcelona: Gedisa, 1992).

KHUN, Thomas Samuel. La estructura de las revoluciones científicas (trad. de Carlos Solis). México D.F.: FCE, 2013.

NÚÑEZ TORRES, Michael. Sobre el principio del efecto directo y primacía del derecho comunitario (Comentario a la sentencia del 24 de abril de 1990 del Tribunal Supremo español en Jurisdicción Contencioso-Administrativa). En: Conocimiento y Cultura Jurídica, No. 1, enerojunio, 2007.

PLATÓN. Diálogos VIII, Leyes (Libros I-VI) (trad. Francisco Lisi). España: Gredos, 2008.

REHNQUIST, William. Constitutional Courts: Comparative Remarks. In: GERMANY AND ITS BASIC LAW: PAST, PRESENT AND FUTURE, A GERMAN-AMERICAN SYMPOSIUM 411, 412 (Paul Kirchhof \& Donald P. Kommers eds., 1993). Cit. por Moon, Cody, Comparative Constitutional Analysis: Should the United States Supreme Court Join the Dialogue?, Journal of Law \& Policy, vol. 12, 2003. En: <http://goo.gl/yiZDaQ>. Fecha de consulta 2 de diciembre de 2015.

SERNA, Pedro. Filosofía del Derecho y paradigmas epistemológicos. De la crisis del positivismo a las teorías de la argumentación y sus problemas. México: Porrúa, 2006.

SLAUGHTER, Anne-Marie. A Typology of Transjudicial Communication. En: University of Richmond Law Review, No. 29, 1994.

ZAGREBELSKY, Gustavo. El derecho dúctil. Ley, derechos, justicia. Novena edición (trad. Marina Gascón). Madrid: Editorial Trotta, 2009.

; Marcenò Valeria. Giustizia costituzionale. Bologna: il Mulino, 2012.

\title{
JUDICIAL DIALOGUE AS HERMENEUTICAL DIALOGUE: HUMAN RIGHTS PERSPECTIVE IN THE DIALOGUE BETWEEN HIGH COURTS AND LOCAL JURISDICTION
}

\begin{abstract}
The purpose of this paper is to show that, from a theoretical point of view, the judicial dialogue has the same structure as a hermeneutic dialogue. Nonetheless, in practice, whether because the legislator so provides it or because of a wrong interpretation of the law, the judicial processes are not always followed by the guidelines of the hermeneutic dialogue. The main axis of this exhibition, founded in philosophical hermeneutics, is that, by making restrictions to the human rights contained in certain precedents issued by the Mexican Supreme Court, it tries to avoid that the judges appeal to the judicial dialogue for the effective protection of human rights. It is concluded that the fact that the Court stays away of its own principle is not, by itself, something that necessarily has to do with an "over interpretation" or tyrannical attitudes. Amongst other reasons, the hermeneutic situation by which it is solved is never the same. But, abandoning one approach for another, in response, of
\end{abstract}


course, to the hermeneutic situation, in a correct interpretation is never to violate rights, but to fully comply with the "purpose" of the Supreme Court and of all the judges: the implementation of justice.

\section{KEYWORDS}

Philosophical Hermeneutics. Judicial dialogue. Hermeneutics dialogue. Interpretation.

Recibido: 19 de diciembre de 2015

Aprobado: 9 de febrero de 2016 